\title{
Intercalando olhares a partir dos registros paroquiais da Madre de Deus de Porto Alegre: a possivel combinação entre macro e micro-história
}

\author{
Merging looks from the parish registers of the Madre de Deus de Porto Alegre: a possible \\ combination of macro and micro-history
}

La fusión de las miradas de los registros parroquiales de la Madre de Deus de Porto Alegre: una posible combinación de macro y micro-historia

Denize Terezinha Leal Freitas*

"Os dias talvez sejam iguais para um relógio, mas não para um homem."

Marcel Proust

\section{Resumo}

O presente artigo aborda as novas tendências da história, o seu diálogo com a antropologia e as diferentes escalas de análise que podem ser combinadas num diálogo que tem se mostrado promissor. Dessas novas abordagens, fez-se uma ponte que a demografia histórica tem atravessado de encontro a história social. Nesse sentido, pretendemos mostrar como as análises quantitativas dos registros paroquiais (casamento, batismo e óbito) podem servir enquanto propulsores do estudo das trajetórias individuais. No jogo de escala proposto, deslocando-se de uma análise macro em direção à micro, objetiva-se indicar quais os passos viáveis de articulação de variadas fontes e métodos para tornar essa combinação possível diante do desafio de pesquisar a história das famílias e da população da Freguesia da Madre de Deus de Porto Alegre nos séculos XVIII e XIX.

Palavras-chave: Registros paroquiais. Família. Freguesia Madre de Deus de Porto Alegre.

\footnotetext{
Doutoranda em História pela Universidade Federal do Rio Grande do Sul (UFRGS). Mestra em História Latino-Americana na Universidade do Vale do Rio dos Sinos (UNISINOS). Coeditora e membro do Conselho Editorial da Revista Brasileira de História \& Ciências Sociais.
}

Recebido em 29/07/2013 Aprovado em 20/09/2013 http://dx.doi.org/10.5335/hdtv.14n.1.3370 


\section{Introdução}

Os caminhos a serem trilhados numa pesquisa dependem majoritariamente da maneira como o sujeito observa e, sobretudo, questiona o seu objeto de estudo. $\mathrm{O}$ diálogo profícuo entre a história e a antropologia permitiu aos historiadores perceberem o quanto as suas investigações seriam enriquecidas a partir de uma nova perspectiva de análise, ${ }^{1}$ propondo-se a lançar novos olhares, questões e métodos.

Para Levi (1992, p. 137), os pesquisadores permitiram interpretações que levassem em consideração outros ângulos do objeto. Em outras palavras, começaram a valorizar "a escala como um objeto de análise que serve para medir as dimensões no campo dos relacionamentos". Esse mergulho microscópico diante das fontes levou os historiadores a uma pluralidade de universos, até então intangíveis.

As contradições sociais, as articulações pessoais (ou coletivas), as discrepâncias, as "anormalidades" que (res)saltaram aos olhos mostraram o quão complexo e ambíguo são os diferentes segmentos que compõem as sociedades no tempo e no espaço. Portanto, mais do que adequar os resultados da pesquisa a um modelo unificado de hipóteses explicativas fechadas, os micro-historiadores aproximam-se dos antropólogos quando flexibilizam a teoria diante dos fatos.

Em vez de se iniciar com uma série de observações e tentativas para impor sobre elas uma teoria do tipo legal, esta perspectiva parte de um conjunto de sinais significativos e tenta ajustá-los em uma estrutura inteligível. A descrição densa serve portanto para registrar por escrito uma série de acontecimentos ou fatos significativos que de outra foram seriam imperceptíveis, mas que podem ser interpretados por sua inserção no contexto, ou seja, no fluxo do discurso social. Essa abordagem é bem-sucedida na utilização da análise microscópica dos acontecimentos mais insignificantes, como um meio de se chegar a conclusões de mais amplo alcance (LEVI, 1992, p. 142).

Obviamente, isso não significa uma abolição dos métodos de análise macro-históricos, pelo contrário, é desses que devem surgir as melhores problemáticas para que o pesquisador questione seus resultados, e sobretudo, duvide das regularidades, esteja sensível às mudanças de comportamento na longa duração e hesite diante das abordagens generalizantes ou simplificadas. Enfim, para que se permita "dar vida e voz" aos sujeitos históricos diluídos nesse todo, procurando atentar aos mais sutis sinais.

Nesse sentido, pretendemos abordar como as análises quantitativas dos registros paroquiais (casamento, batismo e óbito) podem servir enquanto propulsores do estudo das trajetórias individuais. No jogo de escala proposto, deslocando-se de uma análise macro em direção à micro, objetiva-se indicar quais os passos viáveis de articulação de variadas fontes e métodos para tornar essa combinação possível diante do desafio de pesquisar a história das famílias e da população da Freguesia da Madre de Deus de Porto Alegre.

Inicialmente, examinaremos como podemos estabelecer essa relação entre macro e micro-história. Quais as vantagens? Qual a razão dessa necessidade? Como efetivá-la? Num segundo momento, buscar-se-á 
mostrar quais os indícios que nos permitirão viabilizar a ponte analítica através das fontes, tendo como objetivo exemplificar esse exercício microscópico através de casos já estudados e de outros observados.

\section{Do macro para o micro: como articular um diálogo?}

Através da caracterização de quem casou na Freguesia Madre de Deus de Porto Alegre, foi possível averiguar uma série de informações referentes a quem, quando, como e de onde vinham os nubentes que trocaram alianças na localidade. Nesse princípio de investigação, que se tornou alvo de pesquisa da dissertação de mestrado (ver FREITAS, 2011), nosso objetivo central era mapear, isto é, identificar as características gerais de quem contraiu núpcias nesse local.

Contudo, muitas indagações surgiram, dentre elas, em linhas gerais, destacam-se: afinal, quais são as motivações por trás dessas escolhas nupciais? E aquela parcela da população que não se casou sob as bênçãos da Igreja? Nesse sentido, pode-se constatar, a partir da metodologia da demografia histórica, que foi a responsável pela expansão de novos horizontes para a pesquisa, que não podemos separar a análise quantitativa da análise qualitativa. Logo, os dados são o ponto de partida para a análise, e a partir deles, o pesquisador busca levantar suas hipóteses e coordenar a investigação, a fim de compreender sua relevância. Segundo Barros:
Hoje se espera que o historiador " problematize" a morte, o nascimento ou o casamento, que não apenas contabilize os movimentos migratórios, mas que também fale sobre as expectativas culturais e sociais dos migrantes, que recupere um pouco da sua vida da aparente aridez a partir de uma documentação que se utilizada com finalidade meramente estatística, não trará para os leitores de história mais do que um número, verdadeiro, mas abstrato, preciso mas patético, matematicamente descarnado (2004, p. 25).

O estudo dos registros paroquiais de casamento forneceu as bases para que soubéssemos qual o alcance e a importância do matrimônio no cotidiano dessa população livre que ascendia à tal sacramento. Todavia, necessitamos perceber como se davam essas articulações matrimoniais, e por que algumas pessoas optavam por não se casar. Tal possibilidade investigativa se viabiliza a partir do cruzamento nominativo do conjunto dos registros paroquiais (casamento, batismo e óbitos), permitindo identificar os bastidores das outras formas de uniões, além do matrimônio, e os diversos arranjos familiares advindos de dentro e fora dos laços do sétimo sacramento.

Para tanto, buscamos, por meio da trajetória de alguns nubentes e não nubentes, aproximarmo-nos das estratégias familiares, dos tipos de famílias e das possíveis causas que levaram ou não os indivíduos ao altar. Assim, deixaremo-nos conduzir pelo "fio de Ariadne", de acordo com a história social: o nome.

Não obstante, é por meio do nome que o pesquisador identifica o complexo emaranhado de relações e conjunturas sociais nas quais o sujeito está presente. Portanto, ao investigador cabe a tarefa de observar cuidadosamente 
[...] as linhas que convergem para o nome e que dele partem, compondo uma espécie de teia de malha fina, dão ao observador a imagem gráfica do tecido social em que o indivíduo está inserido (GINZBURG, 2004, p. 175).

Tal instrumento metodológico nos servirá de guia, a fim de reconstituirmos algumas das trajetórias da vida familiar que nos permitam caracterizar as famílias e as formas de união que compuseram a sociedade porto-alegrense.

Dessa forma, nossa intenção é adentrar no mundo familiar e descobrir de como aconteciam as uniões da população dessa localidade. Entendemos que se torna imprescindível observar como se davam as práticas de união atravél das gerações, isto é, a metodologia da reconstituição de famílias. Essa metodologia vale-se do que denominamos cruzamento nominativo das fontes. Segundo o estudo intitulado Identifying People in the Past (WRIGLEY, 1973), "é o processo pelo qual, diferentes itens de informação sobre um indivíduo nomeado são associados uns com os outros em um todo coerente, de acordo com certas regras". A incansável busca de reunir informações a respeito de um indivíduo inserido na sociedade fez com que inúmeros demógrafos historiadores ${ }^{2}$, utilizando-se de seus conjuntos de registros paroquiais, realizassem estudos a partir do cruzamento nominativo das fontes. Resumidamente, para Marcílio:

O princípio da reconstituição de famílias é o seguinte: reunir, na medida do possível, as fichas ou levantamentos de batizados, de casamento, e de óbitos de cada um dos esposos; transpor esses dados para a parte da ficha de família destinada a receber as informações relativas ao marido ou à mulher; procurar transcrever (se houver) as informações que elas contêm para a parte das fichas destinadas aos filhos (1977, p. 54).
Daí a importância dos registros de casamento, pois "o casamento é o ponto de partida da família conjugal" (MARCÍLIO, 1977 , p. 54), isto é, cada ficha de família parte de um casamento. Obviamente, outras formas de união serão abordadas na análise, visto que a sucessão das gerações pode apresentar distintos tipos de arranjos conjugais ou a presença de celibatários na família.

O método de Henry foi melhor adaptado pela professora Amorim, ou seja, diferentemente do primeiro, as fichas familiares são realizadas a partir dos indivíduos e não pelos casamentos. Para a realidade luso-brasileira, essa adaptação é a mais adequada à análise das famílias devido aos elevados índices de ilegitimidade. De acordo com Scott, identificamos a "propensão à bastardia" enraizada no Velho Mundo,, neste viés específico, destacando o caso português.

Quando Peter Laslett fez referência à possibilidade de certas áreas do continente europeu apresentarem índices de ilegitimidade elevados e propor existência de subcomunidades com propensão à bastardia, Portugal foi incluído neste cenário, além de outras regiões como a Escandinávia, o sul da Alemanha e a Áustria. Este autor já antevia o caso português com um interesse especial, uma vez que se referiu àquele pequeno país como um "puzzle", isto é um "quebra-cabeças", dada a diversidade de situações que pareciam existir, no que dizia respeito aos seus sistemas familiares (SCOTT, 2005, p. 3).

Portanto, objetivamos mapear e alcançar informações geracionais e, a partir disso, compreender de que forma procuraram, ou não, reproduzir a prática matrimonial com o passar do tempo. Segundo Nascimento, a família tem papel fundamental nas escolhas dos indivíduos, pois: 
É na família que os indivíduos se relacionam e trocam experiências, visto que ela é, ao mesmo tempo, um espaço de conflito cooperativo e um espaço determinante de bem-estar através da distribuição de recursos, passando muitas vezes a refletir diretamente dúvidas, aspirações e questões pessoais. Na família os filhos e demais membros encontram o espaço que lhes garantem a sobrevivência, desenvolvimento, bem-estar e proteção integral através de aportes afetivos e, sobretudo, materiais (2006, p. 2).

De acordo com Faria (1998), não podemos falar em um tipo de família quando referimo-nos à história das famílias brasileiras, sobretudo durante o passado colonial e imperial. Para a autora, a família é múltipla, diversa, plural, portanto, repleta de arranjos e de organizações que se diversificam no tempo e no espaço. Assim, questionamos: que tipos de famílias encontramos em Porto Alegre? Que tipos de uniões prevaleceram? Quais alterações podem ter ocorrido ao longo do tempo e por quê? Enfim, pretende-se problematizar os desfechos familiares tanto do contexto local quanto das possíveis influências externas (uniões entre pessoas que migraram de outras regiões, com indivíduos de outras etnias com religiões e/ou costumes distintos dos luso-brasileiros) a partir do cruzamento nominativo das fontes.

Portanto, munido de um banco de dados, construído a partir dos métodos da demografia histórica, ${ }^{3}$ bem como, tendo à disposição um conjunto de documentação de cunho eclesiástico e civil, pretendemos reconstituir a trajetória familiar de alguns nubentes. Teremos como foco as vivências dos nubentes antes e depois do casamento, visando identificar, a partir do cruzamento das fontes eclesiásticas, as formas de uniões e os tipos de famílias que caracterizaram a população de Porto Alegre, durante as transformações ocorridas entre os finais do século XVIII e durante a primeira metade do século XIX.

A macro e a micro história foram, por muito tempo, relacionadas de maneiras distintas, opostas e como campos diacrônicos, por vezes, totalmente opostos na maneira de historiar. No entanto, o diálogo entre as análises de longa duração com aquelas que privilegiam um estreitamento no foco de investigação a partir dos sujeitos é fundamental para o enriquecimento do trabalho histórico. Tanto que é a partir de uma análise conjuntural que emergem novas indagações, questionamentos e problematizações a serem feitas a respeito do sujeito histórico. Segundo Rosental:

O comportamento social não poderia, portanto simplesmente depender da obediência mecânica a um sistema de normas: sua explicação impõe que se leve em consideração a posição de cada membro da população estudada (1998, p. 156).

Mas isso não significa optar substancialmente apenas por uma perspectiva de análise, mas agregá-las de maneira que os limites de cada escala possa ser superado ou complementado pela outra. Para Revel (2000), as abordagens macro privilegiaram, por muito tempo, um olhar mais apurado sobre as regularidades históricas, baseadas em trabalhos empíricos e dados estatísticos meticulosamente elaborados por uma escrita protocolada e científica. Obviamente, o grande impacto desse tipo de visão histórica teve como consequência um esgotamento em si. 
Não obstante, a escola italiana da década de 1970 com Ginzburg e Levi trouxe à tona as limitações e o enfadamento de abordagens já bastante difundidas pelos macro-historiadores, ${ }^{4}$ os quais chamavam a atenção dos historiadores para perceberem o outro lado da moeda, ou melhor, clamam para que estes reduzam a escala a fim de observar as singularidades e privilegiar um olhar sobre os objetos de maneira mais complexa, concebendo a importância da linguagem, do emprego da palavra, dos silêncios, enfim, a busca de uma ciência do vivido.

Portanto, acreditamos que partindo de uma experiência de análise quantitativa, munidos de uma gama documental transformada em banco de dados e já parcialmente trabalhada, poderemos enriquecer nossa investigação, partindo para a análise micro-histórica. Afinal, previamente encontramos as regularidades matrimoniais de Porto Alegre, mas quais as rupturas, aspectos diferentes e inesperados podem aflorar através de uma mudança de escala de análise?

As análises de caráter quantitativo têm suas limitações e virtualidades. De um lado, fazem aparecer o que está imerso, encobrindo a complexidade da sociedade. Por outro, apontam para novos problemas e direcionamentos de pesquisa. Nesse sentido, estamos convictos, é vital que a metodologia articule-se a análises "micro" (GALVÃO \& NADALIN, 2003, p. 553).

Portanto, é indispensável que haja um caminho do meio entre a análise micro e macro. Logo, pretende-se estudar os aspectos sociais das formas de união sobre outra ótica, pois:
[...] existe assim a possibilidade de reconstruir histórias de famílias e, às vezes, por alguma feliz coincidência de fontes, histórias individuais suficientemente ricas - típicas ou excepcionais -, sendo ainda possível pôr em relevo relações interindividuais contínuas, isto é, estruturadas (por exemplo, relações de débito/crédito) (GRENDI, 2009, p. 23-24).

Buscamos priorizar as relações entre os sujeitos, analisando seus comportamentos, escolhas e atitudes perante sua maleabilidade de interferir nas regularidades sociais. Para Revel (2000, p. 17), o micro-historiador busca "Estudar o social não como um objeto dotado de propriedades, mas sim como um conjunto de inter-relações móveis dentro de configurações em constante adaptação." E mais ainda:

A manipulação deliberada desse jogo de escalas sugere uma paisagem totalmente diferente, ao mesmo tempo que uma outra ideia da representatividade de um caso local. Os acontecimentos são, naturalmente, únicos, mas só podem ser compreendidos, até mesmo em sua particularidade, se forem restituídos aos diferentes níveis de uma dinâmica histórica (2000, p. 35).

De modo geral, tentamos, aqui, perceber as ações individuais não descoladas do social, mas como resultado de uma interação que abre um leque de possibilidades de espaços e temporalidades de atuação. Identificar as estratégias familiares e individuais entrelaçadas, dando ênfase às tensões e às ambiguidades que atravessam as relações sociais. De modo geral, valeremo-nos da micro-história com a finalidade de traçar interpretações cruzadas entre o indivíduo e o social, tendo como fio condutor suas relações familiares atravessadas pelos ciclos vitais visualizados nos batismos, casamentos e óbitos. Assim, vamos à prática de pesquisa. 
Como se aplica na pesquisa?

Objetivamos mostrar na prática alguns estudos de caso que permitiram emergir alguns sujeitos históricos, os quais poderiam ser denominados como "excepcionais normais". ${ }^{5}$ Determinadas trajetórias ou casos particulares de indivíduos destacam-se na aparente homogeneidade dos dados, dentre os quais observamos o caso de Anna Joaquina Rangel de Azeredo e Augusto Guilherme Schroder, (ver FREITAS \& SILVA, 2012) o coadjutor Manoel Marques de Sampaio ${ }^{6}$, entre outros. Exemplificaremos, na sequência, alguns casos em que é possível problematizar questões como maternidades ocultas, bem como paternidades tardias.

\section{0s"casamentos fora do casamento"}

Encontramos casos do que denominamos ser o "casamento fora do casamento", isto é, casais que viviam em condição de concubinato, que constituíram famílias, mas que somente depois de anos vão sacramentar sua união. Conforme os registros estudados, pode-se considerar que, no caso de Jerônimo e Maria Francisca, a ausência do sacramento não impediu que uma nova família fosse constituída, segundo informação retirada do Livro de Registro de Casamentos (1772-1835) da Paróquia Nossa Senhora Madre de Deus Porto Alegre, em seu volume 3:

Aos trinta e hum dias do mez de Dezembro de mil oitocentos e vinte cinco annos nesta Matriz de Nosa Senhora Madre de Deus de Porto Alegre pelas cinco horas da tarde, depois de feitas as diligencias do estilo e não havendo impedimento na forma do Sagrado Concilio Tridentino e
Constituição, por ordem do Reverendissimo Conego Provedor Vigario Geral desta Provincia Antonio Vieira da Soledade perante o Reverendo Coadjuntor Ignacio Soares Viana, se receberão em Matrimonio com palavras de prezente em que expresarão o seu mutuo consentimento Jeronimo Francisco de Vargas viuvo de Vicencia Maria da Conceição com Maria Francisca d' Oliveira, viuva de Antero Joze Pinto, sepultado no cemitério da Freguesia Senhor Bom Jesus do Triunfo, sendo de tudo testemunhas os abaixo asignados, perante os quais declarão os contrahentes que por este Matrimonio subsequente legitimarão, e queirão que legitimados ficassem os seis filhos de ambos havidos de nomes Tristão, Constança, Maria, Clara, Cândida e Anna. E para constar mandei fazer este asento que comigo e as testemunhas e os contrahentes asinei. Dia mez e anno est supra (PARÓQUIA NOSSA SENHORA MADRE DE DEUS PORTO ALEGRE, 1772-1835, p. 150, Livro 3 - grifos nossos).

Assim, para muitos casais, a legitimação de suas uniões tornava-se praticamente inviável. Dentre os principais entraves enfrentados, citamos: os obstáculos envolvendo a partilha dos bens familiares do ex-cônjuge, as disputas patrimoniais entre os filhos e a política da indissolubilidade dos laços contraídos no primeiro matrimônio. Em muitos casos analisados, Figueiredo (1997), constatou que era melhor que viúvos e/ou viúvas não tivessem um novo parceiro e/ou que, quando o tivessem, não legitimassem novas núpcias. Provavelmente, para o casal analisado, a união somente foi legitimada num momento posterior, porque tornou-se inevitável aos olhos da igreja, ou pela decisão dos nubentes em garantir a legitimidade de seus seis filhos. 
Em outros casos, encontramos casais que legitimaram seus filhos e sua união mesmo não estando subordinados aos entraves morais e sociais da viuvez. Pelo contrário, pela quantidade e idade dos filhos, constituíam famílias fora do casamento. Porém, por alguma razão, seja de ordem pessoal, imposição social ou da igreja optaram por legitimara união, garantindo assim, a legitimidade dos filhos.

Em outros casos, chama-nos a atenção o status de quem casa, bem como o tempo de vida conjugal sem os sacramentos do matrimônio. A idade dos filhos no caso a seguir denuncia a existência de "outra forma de união", através da qual observamos um seio familiar fora dos enlaces do casamento.

Aos dezeste dias do mez de Desembro de mil oitocentos trinta e hum annos, nesta Matriz de Nossa Senhora Madre de Deos de Porto Alegre pelas sete horas da tarde depois defeitas as diligencias do estilo, tirados os Depoimentos Dispensados os Proclamas enão resultando impedimento algum na forma do Sagrado Concilio Tridentino e Constituição do Bispado por Ordem do Excelentissimo e Reverendissimo Conego Provizor e Vigario Geral da Provincia Antonio Vieira da Soledade, perante o Reverendo Coadjutor Orestes Rodrigues de Araujo se receberão em Matrimonio com palavras deprezente em que expressarão seo mutuo consentimento o Tenente do Batalhão de Cassadores de Segunda Linha Numero quarenta eseis Jozé Luiz Leite de Castro, filho legitimo de Jozé Luiz Ferreira Lima e de Dona Euzebia Laurinda Leite de Castro, natural da Ferguezia de Prezeto, Bispado de Braga no Reino de Portugal com Dona Floresbella Querubina de Sampayo, natural desta Provincia, filha de pais incognitos: não receberão Bençãos por ser em tempo prohibido, sendo de tudo Testemunha as abaixo assignados perante os quaes declararão estes conjuges que legitimarão equeirão que legitimados ficassem em [virtude] e deste Matrimonio subsequente aos filhos de ambos havidos de nomes Antonio de idade de sete annos e meio, Jozefa de idade de cinco annos e meio, Jozé de idade de hum annos; E para constar mandei fazer este assento, que commigo assignarão os contrahentes e as Testemunhas que tambem aforão deste acto e declararão era este [efeito]

José Joaquim Leite de Castro

Florisbela Querubina de Sampayo

Antonio Jose da Silva Guimarães

Graciano Leopoldo dos Santos Pereira

(PARÓQUIA NOSSA SENHORA MADRE DE DEUS PORTO ALEGRE, 1772-1835, p. 102, Livro 4 - grifo nosso).

Nesse caso, destaca-se o fato de os nubentes não serem viúvos, de representarem uma parcela da população socialmente abastada - como visualizamos pelos títulos e patentes - e de a nubente ter filiação incógnita. ${ }^{7}$ Podemos levantar a hipótese de recrutamento militar, daí a necessidade da legalização da união perante a igreja e o Estado, ou também, outra possibilidade é a situação "escandalosa" dessa família perante a igreja - veja-se a incognicidade dos pais da noiva, visto a mesma possuir titulação de Dona, o que nos remete à grande possibilidade de a mesma advir de uma família abastada - daí a necessidade em regularizar a situação conjugal de tão ilustre família. As hipóteses são as mais diversas, pois as fontes - nesse caso - ocultam-nos as intenções desse típico caso de outras formas de união. 
0s "legítimos" ilegítimos da Madre de Deus

Ao falarmos em ilegitimidade, observamos que os casos "excepcionais normais" que encontramos e abordamos neste trabalho, estão intrinsecamente associados às relações ilícitas. As consequências dos romances furtivos, das aventuras amorosas ou dos relacionamentos duradouros fora dos enlaces matrimoniais, ou seja, daqueles que fugiam da norma, os tornam os casos mais interessantes. Nesses casos, referimo-nos àqueles denominados como "legítimos" ilegítimos: filhos naturais, expostos, filhos de pais incógnitos, etc.

Os expostos são marcados pelo abandono. Nesse sentido, obviamente, a conotação de estigma da rejeição é definida de acordo com a flexibilidade moral de cada sociedade. Contudo, a oportunidade de reconhecimento da paternidade significa mais do que uma nova opção de vida, mas representa o direito a uma identidade legítima. Como no caso de Zeferino, que foi legitimado após sua exposição, na pia batismal:

Aos tres dias do mez de Fevereiro de mil oitocentos e vinte dous annos nesta Matriz de Nossa Senhora Madre de Deos baptizou solennemente o Reverendo Coadjutor Joze de Freitas e Castro e poz os Santos Oleos a Zeferino exposto aos onze de Janeiro proximo em caza de Luiz Antonio Teixeira: forão Padrinhos Zeferino Vieira Rodrigues e Dona Anna Candida Vieira. E para constar mandei fazer este assento que assignei. O abaixo assignado Franscico das Chagas declarou ser Pai do sobredito Zeferino (PARÓQUIA NOSSA SENHORA MADRE DE DEUS PORTO ALEGRE, $6^{\circ}$ LIVRO DE BATISMO, 1820-1828, p. 65).
O batismo de Constança é ainda mais singular, visto que o pároco, inicialmente, declara que ela é filha de "pais incógnitos", isto é, primordialmente, enfatiza-se a necessidade de ocultar a paternidade e, também, a maternidade. Somente ao final do registro é que Jose Apolinario Pereira de Moraes reconhece a dita Constança como sua "filha natural" e "por esse motivo a reconhecia como tal".

Aos vinte e oito dias do mez de Maio de mil oitocentos e vinte e quatro annos nesta Matriz de Nossa Senhora Madre de Deos de Porto Alegre baptizou solennemente o Reverendo Coadjutor Ignacio Soares Viana e por os Santos Oleos a Constança nascido aos vinte e quatro dias do mez de março deste anno, filha de pais incógnitos. Forão Padrinhos Antonio Joze de Moraes e sua mulher Dona Constança Perpetua Fernandes. E declarou no Acto do Baptismo Jose Apolinario Pereira de Moraes que o Recembaptizada era sua filha natural e por este motivo areconhecia como tal. E para constar fiz este assento e declaração que comigo assignou (PARÓQUIA NOSSA SENHORA MADRE DE DEUS PORTO ALEGRE, $6^{\circ}$ LIVRO DE BATISMO, 1820-1828, p. 184v.-185).

De acordo com o que citamos, vale ressaltar que essa legitimidade adquirida não significa que os pais, eventualmente, tornaram legítimas as suas uniões perante os sacramentos do matrimônio. Mas, quer conferir mais do que uma confirmação da bastardia, a possibilidade de tornar-se um herdeiro em potencial, usufruir do cabedal material e imaterial desses pais, valer-se do nome e, quiçá, de sua posição e status social. Portanto, destacamos esse processo de transição da ilegitimidade para a legitimidade como revelador da excepcionalidade desses filhos naturais ou ilegítimos que têm a opor- 
tunidade de valerem-se de alguns privilégios daqueles que são frutos dos legítimos casamentos abençoados pela igreja.

No batismo de Maria, o ocultamento do nome da mãe pode ser um fator importante no que tange à proteção da reputação materna. No caso de mulheres abastadas, constituía-se como um cuidado para não "manchar" a honra familiar e, para as mulheres escravas, como uma estratégia para livrar seus rebentos dos grilhões da escravidão.

Aos vinte seis dias do mez de Agosto de mil oitocentos e vinte annos nesta Matriz de Nossa Senhora Madre de Deos baptizou solennemente o Reverendo Coadjutor Ignacio Soares Viana e poz os Sanctos Oleos a Maria nascida aos dezessete do ditto mez, filha natural de João Ventura e de Mae incognita: neta paterna de Manoel da Silva e de Anna Maria, naturaes da Europa. E no acto do baptismo declarou ditto João Ventura ser o proprio pai da baptizada e que a reconhecia por sua filha: forão Padrinhos Guilherme Florencio Frois e Nossa Senhora. E para constar mandei fazer este assento, que comigo assignou o pai da baptizada (PARÓQUIA NOSSA SENHORA MADRE DE DEUS PORTO ALEGRE, $6^{\circ}$ LIVRO DE BATISMO, 1820-1828, p. 20v.).

Em outros momentos, como no batismo de Belizario, o nome da mãe Francisca Roza aparece sem problemas, visto que a mesma era "crioula forra", isto é, a escravidão não poderia impedir a nomeação, uma vez que a criança nasceu de ventre livre, tampouco houve uma preocupação com uma possível "situação escandalosa", como preveem as constituições. Mas, o que chama atenção no registro, são as informações referenciadas a respeito do pai, a naturalidade e a nomeação dos avós paternos, conforme verificamos a seguir:
Aos trez dias do mez de Dezembro de mil oitocentos e vinte annos nesta Matriz de Nossa Senhora Madre de Deos baptizou solennemente o Reverendo Coadjutor Ignacio Soares Viana e poz os Santos Oleos a Belizario nascido aos dezesseis de Novembro proximo, filho natural de Francisca Rosa crioula forra: forão Padrinhos Antonio Pereira dos Santos e Francisca Antonia Viana. E no acto do baptismo declarou Antonio Jose Pena, natural da Ribeira de Pena, Arcebispado de Braga, filho legítimo de Manoel Martins, e de Maria Gonçalves que ele era o proprio pai do recembaptizado e como tal o reconhecia. E para constar mandei fazer este assento que comigo assignou o sobreditto pai (PARÓQUIA NOSSA SENHORA MADRE DE DEUS PORTO ALEGRE, $6^{\circ}$ LIVRO DE BATISMO, 18201828, p. 27v.).

No que tange à maternidade, encontramos situações de mães naturais, algumas com filhos de pais diferentes. Outras ocultadas, nas quais os registros apenas apontam "mães incógnitas". Algumas arrependidas, como demonstra o cruzamento dos registros das paróquias com as atas da câmara de vereadores, nas quais observamos dois exemplos, percebendoa existência dessas "mães arrependidas." Elas reclamam à Câmara de Vereadores a restituição de seus filhos que foram expostos. Por exemplo, em 19 de janeiro de 1793: "Nesta vereança se mandou entregar o exposto Innocencio a sua mai Thereza de Tal por declarar ser mai do mesmo exposto" (Livro 3 cópia da Atas da Câmara de Vereadores, fl. 218v.), bem como aos 24/01/1829 temos outra Ata que diz que: 
Feliciana Francisca da Conceição, moradora desta Cidade e filha de Abrão Francisco Serpa, morador em Itapuam, aqual confessa que a innocente Maria que foi exposta em doze de setembro do anno passado (1828) em caza de Miguel Manço da Costa, era sua filha, e que a queria criar para cujo fim lhe fosse entregue requeria; e comparecendo também o dito Miguel Manço da Costa, nada appontou sobre a entrega, foi esta mandar fazer e se daliberou matricula respectiva, para mais e não continuar o pagamento pela Camara (Livro 8 de Atas da Câmara de Vereadores, fl. 85).

Nas palavras de Nascimento (2006, p. 45), na maioria das vezes os filhos rejeitados, abandonados e indiferentes por parte de suas mães eram "frutos clandestinos e indesejados de uma vida amorosa e sexual na colônia que encobria uma vasta e complexa gama de relações sexuais". Mulheres desesperadas, mais do que arrependidas, senão apenas das suas eventuais relações ou aventuras esporádicas que geraram consequências, muitas vezes, fardos dolorosos demais para carregarem consigo. Ficaram marcas e estigmas dos abandonos efetivados, conferindo um peso maior do que a gravidade de ser mãe solteira.

A datam de 24 de março do ano de 1785 marca um caso exemplar: o batismo de Ana, filha de pais incógnitos. No registro desse batismo consta apenas o padrinho Antônio da Costa Gouveia e a informação de que foi realizado "in extremis" pelo Pe. Antônio Soares Gil e que criança foi "exposta no rio do Sino da freguesia Nova [Triunfo]" (Livro 1 - 1785 Matriz da Madre de Deus de Porto Alegre, fl. 109 v). Esse abandono, ao que tudo indica, foi em um local totalmente inóspito, no qual as chances de sobrevivência seriam praticamen- te nulas. Isto é, diferentemente de outros tipos de abandono, sobretudo, os domiciliares, indicam um descaso e uma intenção declarada de rejeição sumária do inocente.

\section{Considerações finais}

De modo geral, demonstramos o quanto torna-se possível, senão necessária, a articulação entre a macro e a micro história. Munidos de uma gama documental que permitem cruzamentos tanto verticais, como horizontais, mapeamos inúmeras trajetórias familiares e matrimoniais. Isso se deu tendo por base o conjunto de características gerais dessa sociedade (a partir dos registros paroquiais, como: naturalidades, sazonalidades dos eventos, etc.), que impulsionou a análise de algumas trajetórias individuais.

Esse jogo de escala possibilita ao pesquisador ir além das aparentes coerências reveladas pelos dados estatísticos. Perceber que os homens não atuam de acordo com a sociedade, mas são eles que conferem lógica a essa. Nas palavras de Almeida (2012, p. 154), na maioria das vezes, "os homens agem de acordo com os padrões sociais, estes não são malhas de ferro, havendo sempre possibilidades de escolhas e alternativas, que variam de grupo para grupo, conforme as condições". A sociedade humana é um produto histórico, carregado de intenções, simbologias e sentidos conferidos pelos homens, portanto, passíveis de continuidades e descontinuidades.

Não obstante, alerta-nos Bensa (1998, p. 63) que as situações sociais estão repletas de significados. Cada uma delas é um universo próprio que revela inúmeros caminhos a 
serem trilhados, ou melhor, "fenômenos que têm cada uma sua própria escala temporal e espacial." Constituem um emaranhado de sentimentos, relações, estratégias, interesses e articulações, permitindo um leque de diversas possibilidades de análise.

Então, dar sentido e coerência às variações de escala depende, majoritariamente, da capacidade do pesquisador de conferir inteligibilidade às ações dos atores sociais inseridos no contexto. Lembrando da máxima de Bloch (2001, p. 8) em de que "o mais claro e complacente dos documentos não fala senão quando se sabe interrogá-lo".

\section{Abstract}

This article discusses the new trends of history, its dialogue with anthropology and the different scales of analysis that can be combined in a dialogue that has shown promise. These new approaches, it was a bridge that has crossed Historical Demography against Social History. In this sense, we intend to show how the quantitative analysis of parish records (marriage, baptism and death) can serve as a lever for the study of individual trajectories. In the game of scale proposed moving from a macro analysis towards micro, the objective is to indicate what steps viable articulation of different sources and methods in making this combination possible on the challenge of researching the history of Families and Population Parish of Madre de Deus de Porto Alegre in the eighteenth and nineteenth centuries.

Keywords: Parish registers. Family. Parish Madre de Deus de Porto Alegre.

\section{Resumen}

Este artículo analiza las nuevas tendencias de la historia, la antropología y el diálogo con las diferentes escalas de análisis que se pueden combinar en un diálogo que se ha mostrado prometedora. Estos nuevos enfoques, era un puente que ha cruzado Demografía Histórica contra la Historia Social. En este sentido, tenemos la intención de mostrar cómo el análisis cuantitativo de los registros parroquiales (el matrimonio, el bautismo y la muerte) puede servir como una palanca para el estudio de las trayectorias individuales. En el juego de la escala propuesta pasar de un análisis macro a micro, el objetivo es indicar qué medidas articulación viable de diferentes fuentes y métodos para hacer esta combinación posible en el reto de la investigación de la historia de la Familia y Población Parroquia de la Madre de Deus de Porto Alegre, en los siglos XVIII y XIX.

Palabras clave: Registros parroquiales. La familia. La parroquia Madre de Deus de Porto Alegre.

\section{Notas}

1 Segundo Almeida (2012, p. 152), esse processo ocorreu simultaneamente para antropólogos e historiadores, pois os primeiros "passaram a interessar-se pelos processos de mudanças social, percebendo que seus objetos de estudo não eram imutáveis e estáticos, e os historiadores passaram a valorizar comportamentos, crenças e cotidianos dos homens comuns e tradicionalmente considerados irrelevantes".

2 Dentre eles, podemos citar: Amorim (1991), Macfarlane (1977), Fleury \& Henry (1976) e Scott (1999).

3 Dentre outros estudos que tratam a respeito do assunto, destacamos Scott (2009). 
4 Segundo Marcílio (1984), houve uma profusão de trabalhos na Europa com os métodos da demografia histórica, o que gerou uma estagnação da promoção de novas abordagens históricas. Também Botelho (2004) faz menção a dois fatores que foram fulminantes para esse acontecimento: primeiro, o esgotamento de trabalhos utilizando o método por toda a Europa, e, também, a ascensão da história cultural.

5 Na definição de Ginzburg (1989, p. 177), “o 'excepcional normal' pode ter ainda um outro significado. Se as fontes silenciam e/ou distorcem sistematicamente a realidade social das classes subalternas, um documento que seja realmente excepcional (e, portanto estatisticamente não frequente) pode ser muito revelador do que mil documentos estereotipados. Os casos marginais, como notou Kuhn, põem em causa o velho paradigma e, por isso mesmo ajudam a fundar um novo, mais articulado e rico. Quer dizer, funcionam como espias ou indícios de uma realidade oculta que a documentação, de um modo geral, não deixa transparecer".

6 Padre Coadjutor que aparece como testemunha de muitos casamentos realizados na Paróquia Madre de Deus durante o período de 1772-1809.

7 Segundo Linda Lewin (1995, pág.123), os "filhos de pais incógnitos" eram considerados "espúrios", ou seja, de cópula proibida. No âmbito jurídico, é usado o termo "quoesito", que vem do interrogativo latino "Quaesitus?" (De quem é ele/ela?)".

\section{Referências}

ALMEIDA, Maria Regina Celestino de. História e antropologia. In: CARDOSO, Ciro Flamarion; VAINFAS, Ronaldo. Novos domínios da história. Rio de Janeiro: Elsevier, 2012.

AMORIM, Maria Norberta. Uma metodologia de reconstituição de paróquias. Braga: Universidade do Minho, 1991, p. 42.

BARROS, José D' Assunção. O campo da história: especialidades e abordagens. Rio de Janeiro: Vozes, 2004.

BENSA, Alban. Da micro-história a uma antropologia crítica. In: REVEL, Jacques. Jogos de escalas: a experiência da microanálise. Rio de Janeiro: Ed. Fundação Getúlio Vargas, 1998.
BLOCH, Marc Lepold Benjamim. Apologia da história, ou, o Ofício de historiador. Rio de Janeiro: Jorge Zahar, 2001.

BOTELHO, Tarcísio Rodrigues. História demográfica e história social: convergências e perspectivas. In: ENCONTRO MEMORIAL DO ICHS, 1, 2004, Mariana-MG.

FARIA, Sheila Siqueira de Castro. A colônia em movimento. Rio de Janeiro: Nova Fronteira, 1998.

FREITAS, Denize Terezinha Leal. O casamento na Freguesia Madre de Deus de Porto Alegre: a população livre e suas relações matrimoniais de 1772-1835. 2011. Dissertação (Mestrado em História) - Programa de Pós-graduação em História, Universidade do Vale do Rio dos Sinos, São Leopoldo, 2011.

FREITAS, Denize Terezinha Leal; SILVA, Jonathan Fachini. O nascer e o casar através da trajetória de Anna Rangel: uma possibilidade de estudo das sensibilidades a partir da demografia histórica. Revista Latino-Americana de História, v. 1, n. 2, p. 74-88, 2012. Disponível em: <http://projeto.unisinos.br/rla/index.php/ rla/issue/view/1/showToc>. Acesso em: 18 jan. 2013.

GALVÃO, Rafael Ribas; NADALIN, Sérgio Odilon. Arquivos paroquiais, bastardia e ilegitimidade: mães solteiras na sociedade setecentista. In: V JORNADA SETECENTISTA. Anais... Curitiba-PR, Centro de Documentação e Pesquisa de História dos Domínios Portugueses - Cedope, Departamento de História, UFPR, 2003, p. 538-563.

GINZBURG, Carlo. O nome e o como. In: GINZBURG, Carlo; CASTELNUOVO, Enrico; PONI, Carlo (Orgs.) A micro-história e outros ensaios. Rio de Janeiro: Ed. Bertrand, 1989.

O nome e o como. In: GINZBURG, Carlo; CASTELNUOVO, Enrico; PONI, Carlo (Orgs.) A micro-história e outros ensaios. Lisboa: Difel, 2004. 
GRENDI, Edoardo. Microanálise e história social. In: OLIVEIRA, Mônica Ribeiro de; ALMEIDA, Carla Maria de. (Orgs.). Exercícios de microhistória. Rio de Janeiro: Ed. FGV, 2009. p. 19-38.

MACFARLANE, Alan. Reconstructing Historical Communities. Cambridge: Cambridge University Press, 1977.

LASLETT, Peter et al. Household and family in the past time. Cambridge: University Printing House, 1972.

LEWIN, Linda. Repensando o patriarcado em declínio: de "pai incógnito" a "filho ilegítimo" no direito sucessório brasileiro do século XIX. In: AMORIM, M.N.; SILVA, M. B. N. da. (Orgs.). A Família na História. Revista Ler História, n. 29, 1995.

LEVI, Giovanni. Sobre a micro-história. In: BURKE, Peter (Org.). A Escrita da história: novas perspectivas. São Paulo: UNESP, 1992.

MARCÍLIO, Maria Luiza. Demografia histórica. São Paulo: Novos Umbrais, 1977.

Sistemas demográficos no Brasil do século XIX. In: MARCÍLIO, Maria Luiza (Org.). População e sociedade. Evolução das sociedades pré-industriais. Petrópolis: Vozes, 1984. p. 193-207.

NASCIMENTO, Arlindo Mello do. População e família brasileira: ontem e hoje. In: ENCONTRO NACIONAL DE ESTUDOS POPULACIONAIS, 15, 2006, Caxambu, MG. Anais eletrônicos... Campinas: ABEP, 2006. p. 1-24. Disponível em: <http://www.abep.nepo.unicamp.br/encontro2006/docspdf/ABEP2006_476.pdf>. Acesso em: 20 nov. 2011.

REVEL, Jacques. Prefácio. In: LEVI, Giovanni. A herança imaterial. Trajetória de um exorcista no Piemonte do século XVII. Rio de Janeiro: Civilização Brasileira, 2000. p. 7-37.

ROSENTAL, Paul-André. Construir o "macro" pelo "micro": Fredrik Barth e a "microstoria". In: REVEL, Jacques. Jogos de escalas: a experiência da microanálise. Rio de Janeiro: Ed. FGV, 1998. p. 153-172.
SCOTT, Ana Silvia Volpi. Famílias, formas de união e reprodução social no noroeste português (séculos XVIII e XIX). Guimarães: NEPS, 1999.

Amores ilícitos e bastardia: a família luso-brasileira em questão. JORNADAS ARGENTINAS DE ESTUDOS DE POPLACIÓN, 8, 2005. Tandil: AEPA, Disponível em: <http://www.redaepa.org.ar/jornadas/viii/ AEPA/B19/Volpi\%20Scott.pdf>. Acesso em: 20 jan. 2013.

. NACAOB: una opcion informatizada para historiadores de la familia. In: CELTON, Dora; GHIRARDI, Mónica; CARBONETTI, Adrián (Coord.). Poblaciones históricas: fuentes, métodos y líneas de investigación. Rio de Janeiro: ALAP Editor, 2009.

WRIGLEY, Edward A. Identifying people in the past. London: Edward Arnold Publishers Ltda, 1973. 